\title{
RICOS Y POBRES: SOBRE EL FUNDAMENTO Y ALCANCE DEL DEBER DE AYUDA AL PRÓJIMO*
}

\author{
Macario Alemany \\ Universidad de Alicante
}

RESUMEN. Este artículo trata sobre el fundamento y alcance de la obligación de ayuda al prójimo, a aquellas personas con las que no se tiene un vínculo especial. Se analizan las respuestas dadas a esta cuestión por Ronald DWORKIN, Peter SINGER y Ernesto GaRzón VALDÉs. A partir de ahí, se argumenta a favor del punto de vista de DWORKIN, de acuerdo con el cual para decidir qué hacer - o no hacer- por otras personas debemos preguntarnos qué comportamiento no sería respetuoso con el reconocimiento de la igual importancia de sus vidas.

Palabras clave: Ronald DwORKIN, Peter SInGER, Ernesto GaRzón VALdÉS, pobreza, riqueza, hambre, obligación de ayuda, dignidad.

\section{Rich and Poor People: the Rationale and Scope of the Obligation of Aid to the Strangers}

ABSTRACT. This article deal with the rationale and scope of the obligation of aid to the strangers, people with whom we have no particular connection. It analyzes the answers to this question of Ronald DWORKIN, Peter SINGER and Ernesto GARZÓN VALDÉs. It argues in favour of Ronald DwORKIN's view, according which we have to decide what we must do for —and not do to- other people by asking what bevavios would fail to respect the equal importance of their lives.

Keywords: Ronald Dworkin, Peter Singer, Ernesto GARZón VALDÉs, poverty, affluence, famine, obligation of aid, dignity.

* Fecha de recepción: 22 de julio de 2015. Fecha de aceptación: 22 de septiembre de 2015.

Este trabajo ha sido realizado en el marco del proyecto de investigación «Desarrollo de una concepción argumentativa del derecho», DER2013-42472-P, financiado por el Ministerio de Economía y Competitividad. 


\section{INTRODUCCIÓN}

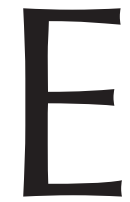

ste artículo trata sobre el problema moral del fundamento y alcance del deber de ayuda al prójimo y, en particular, sobre el escándalo de la desigualdad creciente entre ricos y pobres, de la coexistencia de niveles de riqueza y bienestar desconocidos hasta ahora en la historia con la persistente calamidad de la «pobreza absoluta» ${ }^{1}$. La «pobreza absoluta», de acuerdo con la propuesta de Robert McNamara cuando era presidente del Banco Mundial, se define como «unas condiciones de vida que se caracterizan de tal forma por una desnutrición, analfabetismo, enfermedades, entorno miserable, alta mortalidad infantil y una baja esperanza de vida, que se encuentran por debajo de cualquier definición razonable de decencia humana» (SINGER, 1995: 272) y la «riqueza absoluta» se define como «la situación en la que se disponen de más ingresos de los que se necesitan para satisfacer de forma adecuada todas las necesidades básicas de la vida, teniendo en cuenta cualquier definición razonable de las necesidades humanas» (SINGER, 1995: 275). Si tomamos el hambre como el mejor indicador de la pobreza absoluta, de acuerdo con FAO, en 2015, 794,6 millones de personas están subalimentadas, esto es, casi un 11 por 100 de la población mundial vive en la pobreza absoluta. Por contraposición, unos 1.000 millones de personas en el mundo disfrutan de un elevado nivel de riqueza y bienestar, son «ricos absolutos» (SINGER, 2012: 26). Dentro de este grupo se encuentran los supermillonarios; según Oxfam, en el mundo hay 1.645 milmillonarios, esto es, personas con fortunas superiores a los 1.000 millones de dólares, entre los cuales los 85 más ricos del planeta acumulan la misma riqueza que la mitad más pobre de la humanidad ${ }^{2}$.

Tomas NAGEL ha destacado la tensión entre los puntos de vista personal e impersonal, la cual origina un «conflicto mental» al individuo que delibera sobre qué es lo correcto moralmente (NAGEL, 2006: 21 y ss.). Sostiene NAGEL que «la intuición básica que aparece a partir de la perspectiva impersonal es que la vida de los otros tiene importancia, y nadie es más importante que ningún otro» (NAGEL, 2006: 22). Desde el punto de vista personal, sin embargo, nuestras aspiraciones y valores nos parecen prioritarias, del mismo modo que algunas personas son más importantes que otras y, en consecuencia, estamos más dispuestos a comprometernos moralmente con ellas en especial que con todas en general. Dicho de otro modo, mientras que desde el punto de vista universal o impersonal todos los seres humanos aparecen como el prójimo al que estamos unidos por lazos de solidaridad, desde el punto de vista personal tan sólo algunos seres humanos aparecen como próximos. El «prójimo» sería entonces un concepto relativo que alude a toda persona con la que no se mantiene ningún vínculo especial que lo convierte en próximo, como serían los vínculos políticos, familiares, laborales, de vecindad, iglesia, etc. (GARZÓN VALDÉS, 1986: 17). En este sentido, muchas de las personas que viven en la pobreza absoluta son el prójimo para las personas que viviendo en la opulencia podrían ayudarles.

1 Utilizo el término «calamidad» en el sentido que le atribuye E. GARZÓN VALDÉs: «Aquella desgracia, desastre o miseria que resultan de acciones humanas intencionales, es decir, quedan excluidos los casos que pueden caer bajo la denominación general de la "mala suerte" individual o colectiva o que son consecuencia de actos voluntarios no intencionales». Este concepto se contrapone al de «catástrofe», que resulta inevitable. Vid. GARZÓN VALDÉs, 2012: 16.

2 Vid. el informe de Oxfam: «Iguales». Disponible en http://www.oxfamintermon.org/es/que-hacemos/ proyectos/desigualdad/iguales (3 de septiembre de 2015). 
Al considerar el hecho y la envergadura del sufrimiento humano causados por la carestía de los bienes más básicos (como el alimento, el agua, los tratamientos médicos más sencillos, una mínima higiene, etc.), se suele partir de las siguientes intuiciones:

1) La pobreza absoluta es un estado de cosas intolerable, deónticamente imposible en cualquier sistema moral racional, de modo que ningún argumento moral puede hacer «permisible» dicho estado de $\cos ^{3}{ }^{3}$.

2) Todos y cada uno de nosotros deberíamos hacer algo, o algo más de lo que hacemos, para acabar con (o prevenir) tal estado de cosas moralmente intolerable 4 .

3) La inacción o el conformarnos con prestar una ayuda mínima (casi irrelevante con respecto a nuestra riqueza), no nos hace seriamente responsables de la calamidad de la pobreza, de manera que, a pesar de cierta mala conciencia, podemos seguir considerándonos personas honestas en general.

4) En ciertas circunstancias, tenemos un deber de ayuda al prójimo y, en caso de incumplirlo, somos seriamente responsables del mal que padece.

El paso de este nivel intuitivo incoherente a un nivel crítico o reflexivo coherente no es fácil. La mayoría de autores sostienen el carácter racional de las dos primeras intuiciones - que la pobreza absoluta constituye un mal que debe ser evitado y que estamos obligados en alguna medida a contribuir a su eliminación-, a partir de ampliar la cuarta intuición —nuestra obligación de ayuda en casos especiales-. Se concluye así que la tercera intuición —no somos seriamente responsables de la pobreza— es una simple racionalización de nuestra debilidad de voluntad. El problema es, entonces, determinar la medida de cumplimiento de nuestros deberes generales de ayuda al prójimo. Como veremos, las principales propuestas al respecto son criticadas por ser poco exigentes o por ser demasiado exigentes.

En este artículo quisiera reexaminar la cuestión a la luz de la aportación, relativamente reciente y nueva, que Ronald DwORKIN nos ofrece en su última obra publicada

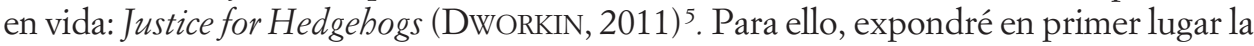
posición de Dworkin y, a continuación, las de Peter Singer y Ernesto GARZÓN VALDÉs. Se trata de dos autores provenientes de tradiciones éticas diferentes: la utilitarista en el caso de SINGER y la deontologista kantiana en el de GARZÓN VALDÉs. Trataré de valorar las mismas por sus propios méritos y en relación con los argumentos de DwORKIN. Finalmente, propondré algunas conclusiones a la luz de las consideraciones efectuadas.

\section{EL PLANTEAMIENTO DE RONALD DWORKIN EN JUSTICE FOR HEDGEHOGS}

\subsection{De la ética a la moral}

Justice for Hedgehogs es un largo y denso tratado en el que DwORKIN desarrolla su concepción de la unidad del valor. Hay una continuidad entre su filosofía jurídica

\footnotetext{
3 Sobre el concepto de «intolerancia»: vid. GARZÓN VALDÉs, 1993.

4 Presupongo que el lector de este artículo es con toda probabilidad un «rico absoluto» en el sentido antes mencionado.

5 Hay traducción al español en el Fondo de Cultura Económica, México, 2014. No será, sin embargo, su última obra original, puesto que se publicará póstumamente Religion Without God.
} 
y su filosofía moral. El método sustancialmente es el mismo: la integración, cuanto más amplia posible mejor, de nuestras creencias, valores, principios, etc., en un todo coherente. Desde esta perspectiva, DWORKIN propone una redefinición de los términos «ética» y «moral» de la siguiente manera: los estándares morales prescriben cómo debemos tratar a los otros y los estándares éticos cómo debemos vivir nuestras propias vidas (DwORKIN, 2011: 191). El proyecto interpretativo consiste en configurar una concepción de lo que es vivir bien que pueda guiarnos en la interpretación de los conceptos morales. En gran medida, nuestro autor retoma la concepción clásica, de PLATÓN y ARISTÓTELES, de acuerdo con la cual el sentido de la vida humana es buscar la felicidad, pero ésta sólo la alcanza quien construye un carácter virtuoso, quien sigue un estilo de vida moral. La idea no puede ser más promisoria: la moral no conspira contra nuestra felicidad, sino que es un elemento constitutivo de la misma. Sin embargo, inmediatamente surge un primer escollo: ¿Acaso la moral no debe ser entendida como categórica, esto es, como independiente de nuestros deseos y aspiraciones? ¿Acaso la moral no constituye un límite para nuestras aspiraciones? ¿Acaso hacer lo correcto no implica, en ocasiones, serios sacrificios? ¿Supone esta estrategia de buscar una coherencia entre la ética y la moral que sólo deberíamos asumir aquellas responsabilidades morales que más nos convienen?

Ante estas preguntas, hay diversas respuestas que tratan de restaurar la unidad entre la ética y la moral. Con frecuencia, se propone como solución distinguir entre el contenido de los principios morales y su justificación. Los principios morales serían, efectivamente, categóricos en su contenido, de manera que si mi obligación es no mentir, dicha obligación valdrá aunque en una ocasión particular fuera de mi conveniencia mentir. De otro lado, la justificación de dichos principios morales sí que apelaría a los intereses a largo plazo de sus destinatarios, de manera que el fundamento de la obligación categórica de no mentir residiría en que la humanidad sale ganando a largo plazo asumiendo la validez de tal obligación. Esta primera respuesta es insatisfactoria: es muy firme la convicción de que tanto la definición como la justificación de los principios morales debe ser independiente de nuestros intereses, incluso considerados a largo plazo. A esta convicción la denomina DWORKIN el punto de vista austero (DWORKIN, 2011: 192). Se diría entonces que estamos abocados a afirmar simplemente que la moral se justifica por sí misma y dejar de argumentar. Nuestro autor pretende, no obstante, ir más allá: pretende que construyamos un orden coherente que refleje nuestra concepción de los deberes, responsabilidades y virtudes morales y, además, que integremos ese orden en una red más amplia de valores. Ésta es, a su juicio, la única vía para cumplir con un principio de la ética, que llama principio de autenticidad, de acuerdo con el cual estamos obligados a preguntarnos qué tipo de integridad moral encaja mejor con la forma en que queremos concebir nuestra personalidad y nuestra vida. Sobre este principio volveremos enseguida, por ahora ya podemos presentar el proyecto de DWORKIN: se trata de reafirmar el carácter categórico de la moral por medio de conectar interpretativamente la moral con la ética entendida como un ideal: nuestras ideas acerca de lo que la moralidad requiere y acerca de cuáles son las mejores ambiciones humanas deben reforzarse mutuamente. Veamos cómo se consigue esto.

Nuestro autor propone distinguir entre «vivir bien» y disfrutar de una «buena vida» (DWORKIN, 2011: 195). «Vivir bien» es luchar por tener una «buena vida», pero sólo respetando ciertos límites esenciales para la dignidad humana. «Vivir bien» es 
nuestra responsabilidad básica, algo que siempre está a nuestro alcance y en cualquier circunstancia. La responsabilidad básica de «vivir bien» se fundamenta en el simple hecho de ser criaturas «auto-conscientes» con vidas que conducir; se fundamenta en el hecho de nuestra mera existencia y en nuestra conciencia de existir. El valor de «vivir bien» reside en la lucha misma, no en el resultado que se alcanza. Se trata, en palabras de nuestro autor, de un valor adverbial. Es necesario, pues, distinguir entre el valor producto de una actuación y el valor de la actuación misma. Un cuadro puede tener un valor producto, y éste puede ser objetivo o subjetivo, pero la actividad de pintarlo puede tener un valor en sí misma, con independencia del destino de la obra.

La moral es esencial para vivir bien, pero en el proyecto coherentista de DworKIN no se trata de que la moralidad defina por sí misma lo que es vivir bien. Más bien al contrario, nuestras responsabilidades éticas deben contribuir a definir nuestras responsabilidades morales. ¿Cuáles son, entonces, los principios éticos? A juicio de nuestro autor, se trataría del principio de auto-respeto y del ya mencionado principio de autenticidad, los cuales constituyen conjuntamente una concepción de la dignidad humana, que se presenta primero como una concepción ética, acerca de cómo debemos vivir nuestras vidas y, a continuación, nos permite identificar el contenido de la moral, el cómo debemos tratar a los demás: los actos inmorales serán aquellos que insultan la dignidad de los otros (DwORKIN, 2011: 203).

El principio de auto-respeto obliga a tomarnos en serio nuestra propia vida. «Vivir bien» es un asunto importante para cada persona. Debemos reconocer que siempre es un error el despreocuparnos sobre cómo vivir. Resulta difícil negar la validez de este principio: incluso una persona que afirmara que tan sólo desea experimentar placer en su vida, debería admitir que el placer es importante para ella, debería admitir que, a salvo de que reconozca una patología, ésa es su idea sobre cómo vivir. El hedonismo más burdo no es una impugnación del principio de auto-respeto, es una respuesta particularmente pobre a la cuestión de cómo vivir bien.

El segundo principio es el de autenticidad. De acuerdo con el mismo, cada persona tiene una especial responsabilidad para identificar lo que cuenta como un éxito en su propia vida. Ambos principios están conectados: precisamente porque tomamos en serio nuestra vida, juzgamos que «vivir bien» significa expresarnos a nosotros mismos, buscar una forma de vida que consideremos correcta para nosotros y nuestras circunstancias. La autenticidad determina la formación de un carácter o estilo de vida propio, que no es simplemente el reflejo de una convención social o de las expectativas de otros. La autenticidad es exigente: por un lado, nos constriñe a no traicionarnos y, por otro lado, nos obliga a asumir la responsabilidad por nuestras decisiones libres. La autenticidad no supone que debamos mantenernos libres de toda influencia y tampoco que la única fuente de valor sea nuestra convicción (o que no haya valores objetivos), supone que no debemos abandonar la responsabilidad de decidir sobre cómo debe ser nuestra vida.

A partir de estos dos principios de la ética, podemos avanzar rápidamente hacia los principios de la moral recordando el imperativo categórico kantiano, de acuerdo con el cual el auto-respeto que demanda el principio de dignidad implica un recíproco respeto por las vidas de los otros seres humanos. La propuesta kantiana es convincente pero, nos advierte DwORKIN, debemos reflexionar sobre su alcance y límites. 
En primer lugar, debemos enfrentarnos a la siguiente alternativa: ¿Valoramos nuestra vida como objetivamente importante en virtud de algo especial de nuestra vida, de manera que sería perfectamente consistente para nosotros no tratar a otros seres humanos como si tuvieran el mismo tipo de importancia? ¿O valoramos nuestra vida de esa manera porque pensamos que toda vida humana es objetivamente importante? (DWORKIN, 2011: 255).

Quienes responden afirmativamente a la primera pregunta asumen un punto de vista «especial» o «particular», de acuerdo con el cual si la vida de otro tiene importancia será porque comparte la propiedad, no universal, que hace importante mi propia vida; un punto de vista que ha sido sostenido ampliamente a lo largo de la historia y sigue estando (demasiado) extendido hoy en día. Un claro ejemplo de esta posición sería el del nazi coherente que admite que sería lícito que lo mataran si se le encontraran restos de sangre judía. Para él, el valor de la vida humana depende de la propiedad no universal (no compartida por todos los seres humanos) de pertenecer a la raza aria. A partir de ahí está dispuesto a reconocer el igual valor de las vidas de todos los arios y el inferior (o nulo) valor de las vidas de todos los no arios (incluso si se diera el caso que él no fuera ario). A juicio de nuestro autor — recordemos que su método es el de la integración-, sería muy difícil sostener seriamente una opinión como ésta e integrarla en un conjunto más amplio de opiniones: los argumentos raciales esgrimidos contra los judíos generan un verdadero caos de incoherencia al ponerse en relación con la mayoría de las ideas comúnmente aceptadas sobre la responsabilidad. Hay que advertir, además, que el principio de dignidad exige respeto por la importancia de nuestra propia vida, pero no exige una admiración o estimación superlativa. El nazi coherente debería sostener la poco plausible veracidad del siguiente enunciado contrafáctico: si se descubriera que soy judío, entonces no tendría ninguna importancia lo que hubiera hecho con mi vida. Parece muy difícil admitir honestamente esta posición especial.

Por el contrario, quienes piensan que toda vida humana es objetivamente importante asumen el punto de vista universal. Este punto de vista ha sido defendido por algunas grandes religiones, por humanistas que consideran a toda vida humana como un prodigio cósmico irrepetible, por las más influyentes concepciones éticas y es, además, acorde con muchas reacciones cotidianas por las cuales nos compadecemos del sufrimiento de los otros seres humanos y lamentamos profundamente su muerte; simplemente porque es una muerte. Todo apunta a que debemos por coherencia admitir la validez de la posición universal.

\section{2. ¿Cuáles son las obligaciones de los «ricos» frente a la «pobreza absoluta»?}

Hemos visto cómo la dignidad es tratada como un principio ético, que marca un ideal sobre cómo debemos vivir nuestras propias vidas, y como un principio moral, que prescribe el respeto por la igual importancia de las vidas de los otros. Cuando tenemos la oportunidad de ayudar al prójimo debemos considerar conjuntamente los dos aspectos: una perspectiva que «integre nuestras esperanzas para nuestras propias vidas con nuestro sentido de la responsabilidad frente a los otros» (DWORKIN, 2011: 272). DwORKIN insiste: «Debemos mostrar un absoluto respeto por la importancia ob- 
jetiva de la vida de cada persona, pero también un absoluto respeto por nuestra propia responsabilidad de hacer algo valioso con nuestra propia vida» (ibid.).

El imperativo de mostrar un «absoluto respeto por la importancia objetiva de la vida de cada persona» se presta a una interpretación ultra-exigente, pero no hay que olvidar que debemos atribuirle significado no independientemente sino a partir de el principio de auto-respeto. Para ello, y siguiendo a KANT, DWORKIN nos propone que tomemos como guía una actitud de respeto hacia los otros y, a partir de ahí, consideremos qué acciones u omisiones son inconsistentes con tal actitud. «Entonces —dice nuestro autor - puedo reconocer la importancia objetiva de las vidas de extraños sin suponer que debo subordinar mi vida e intereses a algún interés colectivo o agregado de todos ellos, o incluso de cualquiera de ellos cuyas necesidades sean más grandes que las mías» (DwORKIN, 2011: 274). En conclusión, la obligación de ayuda surgiría cuando la ignorancia de las necesidades ajenas es inconsistente con el reconocimiento del valor objetivo de sus vidas.

\subsection{El conflicto entre nuestros intereses y los del prójimo}

De acuerdo con lo dicho, podemos dar cierta prioridad a nuestros intereses siempre que ello no suponga desconocer el valor objetivo e igual de la vida de los demás, esto es, siempre que nuestra actitud sea compatible con afirmar honestamente tal valor. Para avanzar en la interpretación de este principio, DwORKIN propone el manejo de un test estructurado en torno a los siguientes tres factores: 1) el daño que puede sufrir la persona que necesita ayuda; 2) el coste que supondría para el rescatador ayudar, y 3 ) el grado de confrontación entre la persona en peligro y el potencial rescatador.

De acuerdo con el primer factor, es importante determinar el nivel y tipo de peligro o necesidad al que se enfrenta el prójimo. El simple hecho de que la situación global de una persona sea peor a la nuestra no hace surgir un deber de ayuda. Igualmente, hay que descartar una medida subjetiva del daño, es decir, no debemos juzgar la gravedad de la situación a partir del juicio de la persona necesitada o en peligro. Conviene advertir que los principios de auto-respeto y autenticidad conllevan responsabilidad por nuestra decisiones. Si una persona considera que un costoso proyecto es vital para ella y que perderlo sería un daño terrible, no puede esperar que los otros estén moralmente obligados a contribuir a su proyecto por esta sola razón. En conclusión, «debemos medir — dice DWORKIN — el peligro o la necesidad de la víctima preguntándonos, no cuan malo cree que es, dados sus planes y ambiciones, sino hasta qué punto le priva de las oportunidades ordinarias que la gente tiene para perseguir cualquier ambición que elijan» (DwORKIN, 2011: 276).

De acuerdo con el segundo factor, sea cual sea la gravedad y el tipo de peligro en que se haya inmerso el prójimo, mi responsabilidad de evitarlo será mayor conforme puedo hacerlo con un menor riesgo o interferencia para mi vida. Cuando puedo salvar a alguien de un grave riesgo a costa de un «riesgo o inconveniente relativamente pequeños para mí mismo» (ibid.), resulta más difícil no hacerlo y sostener al mismo tiempo que tal omisión es consistente con una honesta actitud de objetivo respeto por la vida humana. Por el contrario, cuando el riesgo o el inconveniente es mayor es más 
plausible la negativa a ayudar apelando a la responsabilidad con mi propia vida. Ahora bien, se ha sostenido anteriormente que para valorar el daño que una persona puede sufrir en caso de no ser ayudada, no nos vale un estándar subjetivo determinado por la propia víctima. Pues bien, el problema es si para valorar la intensidad del sacrificio, por el contrario, debemos considerar un estándar subjetivo del rescatador: ¿debemos dar el dinero que habíamos reservado para un nuevo complemento de nuestra sofisticada cámara fotográfica a los hambrientos de África?, ¿podemos dedicar todo nuestro tiempo y dinero a un costoso proyecto personal, por ejemplo, a un museo de arte local?

Según nuestro autor, ciertamente aquí hay una asimetría: puesto que, efectivamente, el coste de ayudar debe ser medido subjetivamente de acuerdo con lo que tal sacrificio significa para quien ayuda, dadas sus ambiciones y plan de vida. Algunos planes de vida requieren de una mayor dedicación y pueden desembocar en una desatención habitual hacia las necesidades de los otros: pensemos, por ejemplo, en los brillantes compositores, escritores o pintores que nos causan admiración, y que se han entregado totalmente a su arte, descuidando las necesidades materiales de los otros no menos que las suyas propias. No obstante, en la mayoría de los casos, para el conjunto de personas que pueden ayudar, hay mucho margen para un compromiso en la lucha contra la pobreza que no suponga un descuido de sus legítimas ambiciones personales. Si basta con dar algo de dinero a una organización de cooperación para ayudar eficazmente a los otros, será más bien extraordinario el caso de alguien que creyera honestamente que hasta el último céntimo de su dinero está comprometido por su plan de vida y que, por tanto, renunciar a ese céntimo supondría no cumplir con el principio de autorespeto. Dicho de otro modo, podemos suponer razonablemente que la casi totalidad de los ciudadanos de las sociedades ricas están seriamente obligados a contribuir económicamente, aunque sea en una pequeña medida, a la lucha contra la pobreza, pues no aportar nada supone con toda seguridad un ostensible desprecio por el igual valor objetivo de la vida humana, un desprecio por la dignidad de los otros.

Es plausible pensar que a un gran número de las personas que no ayudan, estando obligadas moralmente a hacerlo, les falta reflexión moral o son descuidadas con sus obligaciones. Pero es cierto también que hay otra parte de personas que no ayudan porque sus proyectos vitales exigen que se ignore por completo el sufrimiento de los otros $^{6}$. A este respecto, no olvidemos que la primera dimensión del principio de autorespeto es la obligación de vivir bien, de luchar por tener una «buena vida» pero dentro de ciertos límites. Los planes de vida que exigen que se ignore por completo el sufrimiento de los otros merecen ser condenados por violar esos límites éticos. En resumen, aunque el principio ético del auto-respeto fundamenta el que nuestros intereses pesen más que los intereses de los otros en cuanto a las obligaciones de ayuda, la asimetría a nuestro favor está limitada por el propio principio moral de dignidad.

6 DWORKIN es notablemente oscuro en este punto. Se trataría, nos dice, de personas irremediablemente egoístas o fanáticas. Mientras que en el caso de los artistas y científicos, totalmente volcados a su actividad, sus planes de vida reflejan de algún modo un aprecio por el valor objetivo de la vida de los otros, por contraposición los planes de vida de esos egoístas o fanáticos tendrían un valor totalmente autoreferencial: por ejemplo, quien dedica todos sus recursos y esfuerzos en construir un templo a su dios particular. Vid. DwORKIN, 2011: 275-276. 
El tercer factor del test que ha de servirnos de guía para ubicar el límite de nuestros deberes de ayuda es la escala de confrontación. De acuerdo con nuestro autor, esta escala tiene dos dimensiones: La primera es la dimensión de particularización: cuanto más claro es quién será dañado sin mi intervención, más fuerte es el argumento de que tengo un deber de ayuda. La segunda dimensión es la de proximidad: cuanto más directamente me encuentro confrontado con cierto peligro o necesidad, más fuerte es el argumento de que tengo un deber de ayuda. La relevancia moral de esta escala es normalmente rechazada desde puntos de vista impersonales sobre el deber de ayuda, tales como el de Peter SINGER que veremos más adelante. Para DwORKIN, al contrario, esta escala expresa bien la idea de que los comportamientos que consideramos inaceptables son aquellos que muestran desprecio por el valor de las vidas de los otros; juzgamos duramente a quienes en situaciones con un alto grado de particularidad y proximidad no ayudan, porque juzgamos que su conducta es incompatible con el principio moral de dignidad. Ello explicaría la práctica habitual de dedicar recursos extraordinarios para rescatar a personas que han sufrido un accidente, aun cuando esos recursos pudieran ser utilizados de una manera más eficiente: por ejemplo, tratar de salvar a los mineros que han quedado atrapados, porque dejarlos morir sin más se considera indigno. No obstante, y éste es un aspecto decisivo sobre el problema que nos ocupa, la importancia de la escala de confrontación debe ponderarse en relación con los otros dos factores tratados: la medida del daño para la víctima y el coste para el rescatador. Cito a DwORKIN:

El hambre y la enfermedad de un enorme número de personas en África y otros sitios alcanza un nivel muy alto en la escala de las necesidades: incluso una cantidad moderada de ayuda juiciosamente utilizada podría salvar muchas de sus vidas. Su súplica se sitúa también muy bajo en la escala de los costes: grandes sumas pueden dedicarse a ayuda si cada persona de los países ricos dan una cantidad tan pequeña como para que no suponga ninguna diferencia por lo que respecta al éxito en sus vidas. Aquellos que sufren están muy lejos, no tenemos ni idea de quienes son, y menos aun de quienes de ellos morirán, o por qué, si nosotros no contribuimos a fondos generales de ayuda. Si el argumento para un deber de ayuda puntúa suficientemente alto y bajo en las dos primeras escalas, de necesidad y coste, ese deber no puede ser rechazado por sólo una baja puntuación en la tercera escala, la de confrontación (DwORKIN, 2011: 279).

Por último, es importante aclarar que la escala de confrontación no obliga a que ayudemos más a los que están más cerca. Esto es lo que parece presuponer la opinión común de acuerdo con la cual es mejor ayudar a los compatriotas que a los extranjeros. Al menos no hay una razón para actuar así derivada únicamente del respeto por la humanidad (puede haber razones de otro tipo). Más bien al contrario, reconocer la importancia de la escala de confrontación puede orientar el trabajo de quienes promueven la cooperación al desarrollo de sociedades lejanas, puesto que «cuanto más grande sea la publicidad dada al sufrimiento en la distancia, más grande será el deber de responder y la vergüenza de no hacerlo» (DWORKIN, 2011: 280).

\section{4. ¿A quién salvar cuando son muchos los necesitados?}

Cuando son muchos los necesitados y no podemos ayudarlos a todos, cabe plantearse la cuestión de a quién debemos ayudar primero. DwORKIN nos propone que consideremos el siguiente caso: 
Una persona se aferra a un salvavidas en medio de una tormenta que ha destruido su barco; los tiburones la rodean. Otros dos pasajeros se aferran a otro salvavidas unos cien metros más lejos; los tiburones también les rodean. Tú tienes una lancha. Puedes llegar a tiempo a uno de los salvavidas, pero no al otro. Asumiendo que los tres son extraños, ¿tienes un deber de salvar a los dos náufragos y dejar morir al náufrago solitario? (DWORKIN, 2011: 280).

Una plausible respuesta es que siempre debemos intentar ayudar al mayor número y, por tanto, que en un caso así, deberíamos ir hacia el salvavidas al que se aferran dos personas. De acuerdo con esta respuesta, en relación con el problema de la pobreza absoluta, dado que hay zonas enteras del planeta asoladas por el hambre, deberíamos apoyar a aquellas organizaciones que con menos recursos salvan más vidas (el «altruismo eficiente», de acuerdo con SINGER). Sin embargo, desde otro punto de vista, que pone el énfasis en la idea de los derechos, parece que el mismo derecho a ser salvado tendría el náufrago solitario que los otros dos. Volviendo al problema de la pobreza, el mismo derecho a ser salvado tendría quien supone un rescate costoso, que quien podría ser salvado con menos recursos.

A juicio de nuestro autor, este problema se vuelve inmanejable al centrarse demasiado en la cuestión del número, sobre el presupuesto de la posibilidad de maximizar una suerte de utilidad general. La clave está en evaluar si la razón que tenemos para elegir la opción de salvar al náufrago solitario supone negar de algún modo la igual importancia de todas las vidas. Pues bien, hay que decir que la decisión de salvar a uno frente a salvar a dos no es por sí misma necesariamente expresiva de una falta de respeto por la dignidad humana. Recordemos que tenemos derecho a no arriesgar nuestra vida para salvar la de los demás, esto es, a anteponer nuestra vida a la de los otros, sean uno o varios, y que, por tanto, de forma similar es plausible pensar que podamos legítimamente anteponer la vida de un tercero frente a la de otros.

Si la clave está en las razones para preferir una cosa u otra, la pregunta es qué tipo de razones serían incompatibles con el respeto por la dignidad. La respuesta es, para nuestro autor, clara: el respeto por la humanidad excluye aquellas preferencias que pueden ser expresivas de la convicción contraria de que no todas las vidas humanas merecen la misma consideración. Así, por ejemplo, sería inmoral preferir al náufrago solitario porque es de raza aria sobre el presupuesto de que los arios por su raza tienen una vida de mayor valor, pero no lo sería preferirlo simplemente porque es más joven o porque es un brillante músico y la música es muy importante para tu vida o crees que es muy importante para el mundo (DWORKIN, 2011: 281).

A quienes se sientan muy incómodos con esta tesis de DwORKIN, les invito a considerar si permite superar el enredo de la discusión sobre a qué organización de cooperación prestar apoyo. A veces se desata una controversia sobre qué organización ayuda a más personas necesitadas y, por tanto, merece ser apoyada en primer lugar. No quiero entrar en si es posible aclarar qué organización es más eficaz en este sentido puramente agregativo; supongamos que podemos determinar con cierta claridad el nivel de eficacia. La idea es que una persona puede optar legítimamente por apoyar a una organización menos eficaz que a otras, siempre que la razón que tenga para ello no sea por sí misma incompatible con el respeto por la dignidad. A veces, después de pasar una enfermedad grave, nos comprometemos en la lucha contra esa enfermedad, aunque 
sea rara y afecte a pocas personas; otras veces la cooperación es una extensión de los compromisos éticos: por ejemplo, quienes ayudan a los necesitados en el ámbito de su profesión, etc. Todas ellas son razones legítimas y no merecen reproche moral alguno.

Por último, el que podamos tener una buena razón, respetuosa con el principio de dignidad, para salvar a los menos en lugar de a los más, no obsta para que en ausencia de ese tipo de razones sea valido el principio de que es mejor salvar más que menos vidas humanas.

\section{PETER SINGER: ENTRE EL ARGUMENTO FILOSÓFICO Y EL ESTÁNDAR RAZONABLE O REALISTA}

\subsection{El estándar de lo «moralmente comparable o significativo»}

Peter SINGER es, sin duda, uno de los filósofos morales más influyentes en la actualidad y, en particular, una de las referencias obligadas en la discusión sobre el problema moral de la pobreza absoluta. Su artículo de 1972, «Famine, Affluence and Morality» ha llegado a convertirse en la mejor ilustración de aquellas posiciones que podrían calificarse como «exigentes» o «ultra-exigentes», en cuanto al alcance de los deberes de ayuda al prójimo. Con frecuencia, se habla de la «postura de SINGER» como un sinónimo de «postura ultra-exigente» y muchos ven en la misma, más que una solución al problema, uno de los cuernos del dilema al que parece abocarnos ${ }^{7}$. Tan sólo santos o héroes, se dice, están en condiciones de cumplir con los estándares de SINGER, en la medida en que es absurdo exigir como un deber general aquello que sólo pueden cumplir personas excepcionales, de modo que el problema no está resuelto; SINGER fracasa. Sin embargo, como veremos inmediatamente, las tesis de SINGER distan de ser tan simples como estas críticas sugieren y, aunque él mismo no parece estar del todo incómodo con la etiqueta de radicalismo, lo cierto es que sus argumentos pueden ser interpretados bajo una mejor luz.

SINGER sostiene un sencillo argumento en el que aceptadas las premisas nos vemos constreñidos lógicamente a aceptar la solución:

Primera premisa: El sufrimiento y la muerte por falta de comida, refugio o asistencia médica son malos.

Segunda premisa: Si tenemos capacidad (el poder) de evitar que ocurra algo malo, sin sacrificar por ello nada de importancia moral equivalente, debemos moralmente hacerlo.

Conclusión: Si tenemos capacidad de evitar el sufrimiento y la muerte por falta de comida, refugio o asistencia médica, sin sacrificar por ello nada de importancia moral equivalente, debemos moralmente hacerlo (SINGER, 1972: 231).

Para SINGER, la primera premisa (o principio) no necesita de ulterior argumentación para su aceptación y, aunque pudiera ser que alguien defendiera el excéntrico punto de vista contrario, se dirige sólo a los que la aceptan (la inmensa mayoría). La segunda premisa (o principio) le parece «casi tan incontrovertible como la primera»

7 BAYÓN recoge, por ejemplo, el comentario de Henry SHUE sobre las implicaciones, de acuerdo con FISHKIN, de asumir un punto de vista imparcial en relación con los necesitados: una moralidad que poca gente estaría dispuesta a aceptar «aparte de unos cuantos santos y de Peter Singer» (BAYÓN, 1986: 53). 
(ibid.). «Sin sacrificar nada de importancia moral equivalente» significa que «la acción de ayuda no sea la causa de algún mal comparable al que se evita, o que implique hacer algo malo en sí mismo, o que suponga dejar de promover algún bien moral, comparable en importancia al mal que podemos evitar» (ibid.). Se trata por tanto, afirma nuestro autor, de evitar lo que es malo y no de promover lo que es bueno ${ }^{8}$, siempre hasta el límite de no sacrificar algo de importancia moral equivalente.

No obstante lo anterior, SINGER admite una versión especial de este principio de acuerdo con la cual «si tenemos el poder de evitar que ocurra algo muy malo, sin sacrificar nada de importancia moral (morally significant), debemos, moralmente, hacerlo» (SINGER, 1972: 231). Vemos que lo que cambia de la versión original del principio a su versión especial es la desaparición de la palabra «equivalente». En el conocido ejemplo del niño que está ahogándose y al que podemos salvar, sin más inconveniente que mojarnos la ropa, este hecho es, a juicio de nuestro autor, algo moralmente insignificante.

La versión cualificada o especial sería menos exigente pero —advierte SINGER-, de su aplicación se derivarían cambios radicales en el estilo de vida de la mayoría de los habitantes de los países ricos por dos razones: primera, el principio se aplica sin tomar en consideración la proximidad o la distancia con la persona que necesita ayuda y, segunda, el principio se aplica sin tomar en consideración si yo soy la única persona en condiciones de ayudar o soy uno entre millones en la misma posición (SINGER, 1972: 232).

$\mathrm{El}$ argumento esencial de SINGER no ha variado sustancialmente a lo largo de los años ${ }^{9}$. Peter SINGER admite que cada individuo debe juzgar qué constituiría para él un sacrificio casi tan importante (equivalente o significativo) en relación con el mal que

8 Como veremos más adelante en la exposición sobre GARZÓn VALDÉs, éste es uno de los puntos más controvertidos en la discusión sobre la existencia de deberes de ayuda al prójimo. Para SINGER, el problema surge por el compromiso con una concepción deontológica de la ética: «Una ética que consiste en deberes específicos, prescritos por normas morales que todo el mundo debe obedecer, debe de hacer una distinción moral tajante entre los actos y las omisiones. Por ejemplo, tomemos la norma: "No matarás". Si esta norma se interpreta, tal como se ha hecho en la tradición occidental, como la prohibición sólo de quitar la vida humana inocente, no es demasiado difícil evitar cometer actos que la violen abiertamente: hay pocos asesinos entre nosotros. Pero, no es tan fácil evitar dejar que mueran seres humanos inocentes. Muchas personas mueren debido a la falta de alimentos, o de servicios médicos adecuados. Si podemos ayudar a algunos, pero no lo hacemos, les estamos dejando morir. Aplicar la norma en contra de matar a las omisiones haría que vivir de acuerdo con ella fuese un símbolo de santidad o de heroísmo moral, en lugar de ser el requisito mínimo de toda persona moralmente decente.

Por tanto, una ética que juzga los actos de acuerdo con que violen o no normas morales específicas debe dar gran peso moral a la distinción entre actos y omisiones. Una ética que juzga los actos por sus consecuencias no lo hará así, ya que las consecuencias de un acto y de una omisión a menudo serán, en todos los aspectos significativos, indistinguibles» (SINGER, 1995: 256).

9 Años después, en 1980, en su famoso libro de Ética práctica, SINGER vuelve a fundamentar el deber general de ayuda a los más necesitados en un sencillo argumento, similar pero no idéntico:

«Primera premisa: si podemos evitar que ocurra algo malo sin sacrificar nada de una importancia moral comparable, debemos hacerlo.

Segunda premisa: la pobreza absoluta es mala.

Tercera premisa: hay parte de la pobreza absoluta que podemos evitar sin sacrificar nada de una importancia moral comparable.

Conclusión: debemos evitar parte de la pobreza absoluta» (SINGER, 1995: 287).

Aquí vemos que SINGER, al tiempo que mantiene la primera versión de su estándar, la que se refiere al sacrificio de algo de importancia moral comparable o equivalente, limita la conclusión a evitar una parte de la pobreza. De este modo, de un lado, salva la objeción de que «debe implica puede» y, por tanto, no puede existir un deber de acabar con toda la pobreza absoluta. 
se pretende evitar, lo cual, reconoce, «variará según el punto de vista ético que uno acepte» (SINGER, 1995: 289). Sin embargo, con ello no está afirmando, como sí lo hace DWORKIN, que el sacrificio que implica la ayuda deba medirse a partir de un estándar subjetivo de quien ayuda. SINGER entiende que, a la hora de determinar qué es un sacrificio excesivo, debemos considerar imparcialmente nuestros intereses y los de los demás, esto es, el que un interés sea nuestro no es ninguna razón para darle más peso frente a los intereses de los demás. De ahí que el estándar de exigencia moral que se deriva del argumento de SINGER sea muy elevado, demasiado si atendemos a que son muy pocos los que pueden cumplirlo (el propio SINGER reconoce su fracaso al respecto), ya que implica cambios radicales en nuestra manera de vivir y en nuestra manera de concebir la libertad de vivir. Dicho de otro modo, el «conflicto mental» entre el punto de vista personal y el impersonal al que antes se aludía parece resolverse de manera radical en favor de este último.

\subsection{El estándar público o realista}

No obstante, SINGER ha terminado por defender un estándar «razonable» o «realista» que sería el adecuado como «estándar público» dadas ciertas asunciones básicas sobre la psicología humana y las circunstancias del mundo contemporáneo. SINGER sostiene que dichas consideraciones sobre la psicología humana (por ejemplo, la dificultad para comprometerse con los intereses de personas anónimas que viven en lugares alejados, geográfica y culturalmente) no tienen relevancia en una reflexión individual sobre lo que debemos moralmente hacer, pero sí la tienen en relación con la deliberación sobre qué normas o estándares deben ser públicamente defendidos, puesto que la moral es de poca utilidad para la humanidad si sus mandatos están condenados, por exigentes, a no ser seguidos (SINGER, 2012: 163 y ss.). De esta manera, la propuesta realista pone el acento en el carácter divisible de la obligación de eliminar la pobreza absoluta y, a partir de este presupuesto, en lo limitado del sacrificio que a cada uno le correspondería. En concreto, SINGER sugiere que deberíamos contribuir entre un 1 y un 5 por 100 de nuestros ingresos dependiendo del nivel de riqueza ${ }^{10}$.

SINGER sostiene que frente a terceros es mejor defender un estándar realizable como el que se acaba de señalar, porque ello alentará una cultura de la donación y, en definitiva, quienes viven en la pobreza recibirán mayor cantidad de ayuda (SINGER, 2012: 164). Pero ello es compatible con afirmar que el razonamiento moral exigente,

En su reciente libro, Salvar una vida. Cómo terminar con la pobreza (2012), SINGER continua defendiendo el que ahora llama argumento esencial, básicamente con la misma forma:

«Primera premisa: El sufrimiento y la muerte por falta de alimento, cobijo y atención médica son malos.

Segunda premisa: Si podemos impedir que suceda algo malo sin sacrificar nada tan importante como el mal que pretendemos evitar, es incorrecto no hacerlo.

Tercera premisa: Aportar dinero a organismos de ayuda internacional puede impedir el sufrimiento y la muerte por falta de alimento, cobijo o atención médica, sin sacrificar nada tan importante como los males que vamos a evitar.

Conclusión: Por consiguiente, si no aportamos dinero a organismos de ayuda internacional, estamos haciendo algo incorrecto» (SINGER, 2012: 33).

10 Si quieren más información al respecto pueden visitar la página web «The live you can save» ( $w w w$. thelifeyoucansave.com). 
el argumento esencial, es irrefutable. Se produce, entonces, la paradoja de afirmar que una persona que hace tan sólo la parte que le correspondería (en un reparto ideal de obligaciones alicuotas) cumple con su obligación y, simultáneamente, esa persona tienen la obligación de contribuir hasta el límite de no sacrificar nada de importancia moral comparable. La paradoja se disuelve afirmando la diferencia «entre lo que debo hacer como individuo y el conjunto de principios o el código moral que debería defender y tratar de que cumplieran la mayor parte de las personas de nuestra sociedad» (SINGER, 2012: 164). Para SiNGER, la tradición kantiana que hace de la publicidad y la universalidad una condición necesaria de la justificación de los principios pasa por alto cuestiones relativas al estadio de la evolución humana y, en particular, ciertos «sesgos» de nuestra psicología.

La noción de «sesgo» que maneja nuestro autor se corresponde con la teoría en auge de los sesgos y de los heurísticos desarrollada, entre otros, por el premio Nobel Daniel KaHNEMAN. Se trata de limitaciones generales del pensamiento humano: errores frecuentes que afectan de forma general (no patológicos) a todos los seres humanos. En el tema que nos ocupa, por ejemplo, un sesgo importante sería el que se puede denominar «efecto de la víctima identificada», el cual sería consecuencia de la interacción de dos diferentes sistemas para conocer la realidad: el sistema afectivo y el sistema deliberativo (SLOVIC, 2007) ${ }^{11}$. Los otros sesgos que toma en consideración Peter SINGER son los siguientes: el «provincianismo», por el que nuestro sistema afectivo se ve más perturbado por la desgracia de los parientes o personas pertenecientes a nuestra comunidad que por la de los extranjeros o desconocidos, como consecuencia de un proceso evolutivo de millones de años orientado a la transmisión de los genes propios; el «pensamiento de la futilidad», de acuerdo con el cual valoramos mejor una situación en la que la proporción de salvados con respecto al número total de personas en peligro es alta, frente a otra situación en la que dicha proporción es menor pero el número de salvados total es mayor ${ }^{12}$; la «disolución de la responsabilidad» o «efecto espectador», por el cual es menos probable que ayudemos si la responsabilidad de hacerlo puede ser compartida; el «sentido de la justicia» por el que se reduce nuestra disposición a hacer nuestra parte si los demás no hacen la suya; el efecto del «dinero», por el cual, la presencia del dinero en una relación social disminuye nuestra predisposición a pedir ayuda o a prestarla y para aproximarnos a los demás (SINGER, 2012: 63-76) ${ }^{13}$.

Ninguno de estos hechos de la psicología humana tiene, en opinión de nuestro autor, fuerza justificativa, pero deben ser tenidos en cuenta para promover una cultura de la donación. Ahora bien, SINGER no se contenta con promover un adecuado «marketing» de la cooperación o, incluso, una suerte de paternalismo libertario, como el defendido por THALER y SunSTEIN (2009), pero de tipo moral, que trataría de favorecer las respuestas correctas (filantrópicamente) por medio de pequeños empujoncitos (nudges), tal y como sería la posibilidad de elogiar a quienes ayudan en algo. SINGER parece abogar por un paternalismo moral fuerte en el que se sostenga públicamente una noble mentira. Su propuesta sólo puede ser efectiva si los individuos creen real-

11 Citado por SINGER, 2012: 66.

12 Así es mayor la disposición para ayudar a salvar al 80 por 100 de 100 vidas en peligro que para salvar el 20 por 100 de 1.000 vidas en peligro. Vid. SLOVIC, cit., y SiNGER, 2012: 70 y 71.

13 SINGER ha desarrollado este tema en The expanding circle: Ethics and sociobiology, 1981. 
mente que cumplen sus obligaciones de ayuda al prójimo contribuyendo en la pequeña parte que les correspondería si todos los demás en situación de ayudar hicieran lo propio. Sin embargo, en primera persona, como reconoce el propio SINGER, se violaría el principio de autenticidad al pensar tal cosa: una vez cumplida mi obligación según el estándar realista, persiste la obligación de contribuir hasta el límite de poner en riesgo algo de valor moral comparable o significativo, seguiría siendo cierto que mi renuncia a ayudar equivaldría a la del paseante que, por evitar mojarse los zapatos y llegar tarde a su cita, no rescata a un niño que se ahoga en el estanque (SINGER, 2012: 165).

\subsection{Observaciones críticas al planteamiento de SINGER}

Peter SINGER ha hecho, en mi opinión, una contribución extraordinaria al desarrollo de una ética racional y práctica. Se trata, como DwORKIN, de un brillante argumentador y en su obra podemos encontrar innumerables ejemplos de buenas argumentaciones en relación con casi todas las discusiones importantes de las últimas décadas. Puede decirse que SINGER es un «filósofo ilustrado» que ha llevado, y sigue haciéndolo, la luz a muchas zonas oscuras del pensamiento moral contemporáneo (por poner sólo un ejemplo: a la cuestión de cómo debemos tratar a los animales). Sin embargo, en relación con la fundamentación y alcance de los deberes de ayuda su propuesta no supera, a mi juicio, algunas críticas, como sí lo hace la propuesta de DwORKIN.

Una primera dificultad tiene que ver con el consecuencialismo de SINGER, por contraposición al deontologismo principialista de DWORKIN. Todo el desarrollo de SINGER en torno al problema del hambre está sujeto a la crítica clásica al utilitarismo: no sabemos hasta dónde debemos llevar el cálculo de consecuencias favorables y desfavorables. El ejemplo del niño que se ahoga en el estanque es lo suficientemente simple como para que no surja este problema del cálculo de las consecuencias. Sin embargo, más allá de este sencillo supuesto, la crítica se aplica con contundencia. El propio SINGER reconoce que una persona comprometida con su estándar de ayuda debería reservar recursos si es que estos le van a llevar a ganar más y a mejorar su capacidad de ayudar; igualmente elogia a quienes han optado por una formación académica de élite para dedicarse a una actividad tan lucrativa como la de agente de bolsa y así adquirir una enorme capacidad de ayuda a los otros. Pero estas «reservas» y orientaciones de los recursos pueden hacerse en muchas direcciones: yo puedo reservar recursos para que mis hijos adquieran una formación que, además, les llevará a un mejor posicionamiento económico que, en su caso, les llevará a ser más capaces de donar; puedo alimentar una industria de lujo si la misma, además de su escaso impacto medioambiental, permite concentraciones de capital que, llegado el caso, pudieran ser puestas al servicio de la filantropía, etc. Igualmente, la cultura de la donación puede alegrarse de que el matrimonio Gates dedique 29.000 millones de dólares a su fundación (algo que Peter SINGER elogia), pero deberíamos preguntarnos si también merece una evaluación positiva el proceso de acumulación capitalista por el que dos personas pueden decidir ser filántropos con 29.000 millones de dólares.

La segunda crítica se dirige contra el excesivo peso que, en mi opinión, SINGER concede a la argumentación lógica, lo cual contrasta con el método hermenéutico y 
de balance de razones de DwORKIN. Recordemos la insistencia de SINGER en que el argumento esencial es lógico y que, en consecuencia, ninguna consideración ulterior hará que deje de ser cierto. El argumento esencial tal y como lo presenta es deductivo (si se aceptan las premisas, debe aceptarse la conclusión), pero no hay que olvidar que la fuerza persuasiva de la lógica sólo es plena en argumentos puramente formales. Cuando los argumentos son sustanciales (tienen contenido), aunque su forma sea lógica ${ }^{14}$ el peso que debemos concederles depende de la interpretación de las premisas y su aceptabilidad, la dimensión material, y del contexto en el que se argumenta, la dimensión pragmática (ATIENZA, 2013: 110 y ss.). En cuanto al valor del argumento por su dimensión material, la cuestión más importante es la interpretación correcta del estándar «sin sacrificar por ello nada de importancia moral equivalente». El estándar tiene un alto grado de indeterminación y también podría decirse que tiene un cierto grado de formalidad. Esto no es necesariamente un defecto siempre que contemos con una definición operativa o un método para precisar y aplicar el estándar. El problema es que SINGER se limita a aludir a algún ejemplo (el niño que se ahoga en el estanque) y a señalar que de aplicar el estándar se seguirían drásticos cambios en la forma de vida de los habitantes de los países ricos. Creo que DwORKIN, y cualquier filósofo moral, podrían asumir el argumento esencial de Peter SINGER, pero partiendo de una interpretación diferente de qué tiene importancia moral.

En cuanto al valor del argumento esencial por su dimensión pragmática, el propio SINGER reconoce su poco peso, puesto que parece que sólo sería persuasivo (y movería a la acción) ante un auditorio de seres angelicales (un auditorio universal perelmaniano, construido con los rasgos más ideales imaginables). De ahí que proponga el estándar público o sensato. Esta disociación, en el campo de la argumentación moral, entre el argumento válido o verdadero y el argumento sensato o público es, a mi juicio, muy insatisfactoria. Para evitar estas disociaciones hay que asumir cierto pragmatismo, del que DwORKIN, NiNO o ATIENZA son claros exponentes, y que aconseja aceptar que la propuesta sensata es, todo considerado, la propuesta correcta: la razonabilidad es una exigencia de la corrección, no una cuestión puramente estratégica ${ }^{15}$. SINGER exige para refutar su posición una demostración, cuando lo único que podemos ofrecerle (y, ciertamente, que él mismo puede ofrecernos) es una argumentación en la que, por ejemplo, las dificultades generales para cumplir con determinado deber y las prácticas de reproche o elogio en relación con ello cuenten, tengan cierto peso, a la hora de considerar la existencia o el alcance de tal deber.

En cuarto lugar, en mi opinión, SINGER no da cuenta suficientemente del valor de la autonomía. De los tres valores clásicos de la tradición kantiana, al tratar el tema

14 Siguiendo a ATIENZA, entiendo aquí por «forma de un argumento aquello que queda del mismo cuando se hace abstracción del significado concreto de las proposiciones que lo componen y del contexto en el que se argumenta» (ATIENZA, 2013: 171).

15 Hay muchos ejemplos a lo largo de la disertación de SINGER en los que encontramos un razonamiento «more geométrico» que nos conduce a una conclusión cuanto menos muy alejada de las opiniones comunes al respecto. Tampoco es inusual la referencia a la idea demostración, necesariedad de la conclusión, etc. Por ejemplo: «La dificultad de cumplir a rajatabla con el deber de salvar a todo el que se pueda — afirma SINGERhace que sea inapropiado culpar a los que se quedan cortos en la consecución de ese objetivo, del mismo modo que culpamos a los que matan; pero esto no demuestra que el acto en sí mismo sea menos grave» (SINGER, 1995: 284). 
de la pobreza, prácticamente se ocupa sólo del que se presta a una interpretación más formal: la universalidad, imparcialidad, regla de justicia formal, etc. Afirma que la imparcialidad es central en el discurso moral y da por supuesto que esta afirmación implica que en todo nivel de discurso moral el razonamiento parcial es inadecuado; de algún modo, se presupone aquello que debía probarse. Por el contrario, parece claro que cabría distinguir entre el principio universal de autonomía que nos permite moralmente atribuir algo más de peso a nuestros intereses que a los de los demás, con el límite de no ofender su dignidad, y la aplicación del mismo a un caso particular en el que el individuo en virtud de un principio imparcial y universal aplica un estándar parcial. Juan Carlos BAYÓN sugiere, utilizando la teoría de la razón práctica de RAZ, que el principio de autonomía provee de razones de segundo orden, en particular de permisos excluyentes, que autorizan al individuo a no hacer aquello que debería hacer según el balance de razones de primer orden (BAYÓN, 1986: 49; RAZ, 1991: 39 y ss.). De cualquier modo, el valor de autonomía parece esencial para interpretar el estándar de aquello que es de «importancia moral equivalente».

Recordemos que en la concepción de DwORKIN la «moral», que prescribe cómo debemos tratar a los otros, es esencial para «vivir bien», pero no se trata de que la moral defina por sí misma lo que es vivir bien; más bien al contrario, nuestras responsabilidades éticas deben contribuir a definir nuestras responsabilidades morales. El estándar defendido por SINGER como moralmente verdadero, dada la enormidad del fenómeno de la pobreza absoluta, no nos deja espacio para definir lo que cuenta como éxito en nuestra propia vida; nuestra autonomía queda reducida prácticamente a elegir cumplir con el estándar o no. Si optamos por ser morales, nuestros recursos deberían quedar reducidos (idealmente) al mínimo, con el límite de retener lo que sea necesario para una eficiente reproducción de los mismos que nos permita seguir contribuyendo y, a la vez, no convertirnos en un carga para los demás. En todo caso, nuestras vidas se definen, en primer lugar, en función de las necesidades de los demás, que deben ser satisfechas.

Todas las críticas anteriores se aplican a la piedra angular del discurso de SINGER: el famoso caso del niño que se ahoga y que puede ser rescatado con un pequeño coste. En este caso se apoya una y otra vez para fundamentar la existencia de un deber de ayuda hasta el límite del sacrificio de algo de valor moral equivalente. Sin embargo, la realidad se parece más a la estrambótica situación de una sucesión interminable de estanques en el que siempre hay un niño ahogándose. Después de salvar a uno, estoy lo suficiente cerca del siguiente estanque para salvar a otro y luego a otro, etc. Incluso en una situación así, donde el sufrimiento y la muerte evitables me asaltan en la proximidad, terminaríamos por construir un compromiso entre nuestros intereses y los de los niños, por más que algunos de mis intereses (descansar, tener relación con mis seres queridos, continuar con algún proyecto esencial para mí, etc.) no fueran de importancia moral equivalente bajo una regla de imparcialidad. El verdadero desafío para el pensamiento moral es incorporar un principio de ayuda a los necesitados sobre los presupuestos del reconocimiento del valor de la autonomía individual y la igual dignidad.

En último lugar, quisiera señalar que el estándar público o sensato, de acuerdo con el cual estamos obligados a cumplir con lo que sería justo, esto es, lo que nos correspondería si los demás también hicieran su parte, resulta, en mi opinión, ridí- 
culo en relación con los muy ricos. Por mucho que la parte que le corresponda a un super multimillonario sea progresivamente mayor que la que corresponda a otros menos afortunados, los modos de vida que los primeros suelen protagonizar son en sí mismos incompatibles con el respeto por el igual valor objetivo de la vida humana. El propio SINGER, criticando la ostentación y el derroche de Larry Ellison, el consejero delegado de la compañía Oracle, afirma que «ha llegado el momento de dejar de creer que aunque esta forma de gastar dinero es estúpida, se trata sólo de una inofensiva exhibición de vanidad, y de empezar a pensar que es muestra de una profunda falta de consideración hacia los demás» (SINGER, 2012: 171).

\section{GARZÓN VALDÉS Y LA OBLIGACIÓN DE LLEVAR A CABO UN SACRIFICIO TRIVIAL}

\subsection{El planteamiento de GARZÓN VALDÉS en «Los deberes positivos generales y su fundamentación»}

Ernesto GARZÓN VALDÉS, en un influyente artículo titulado «Los deberes positivos generales y su fundamentación», ha defendido la validez de los «deberes positivos generales» definidos como aquellos «cuyo contenido es una acción de asistencia al prójimo que requiere un sacrificio trivial y cuya existencia no depende de la identidad del obligado ni de la del (o de los) los destinatario(s) y tampoco es el resultado de algún tipo de relación contractual previa» (GARZÓN VALDÉs, 1986: 17). La propuesta de GARZÓN VALDÉS trata de refutar aquellos argumentos provenientes de cierta tradición liberal de acuerdo con la cual las únicas obligaciones morales generales (esto es, independientes de la identidad del beneficiado) son obligaciones de abstención (por ejemplo, no matar, no robar, etc.), pero nunca, o raramente, obligaciones de acción (por ejemplo, ayudar a los necesitados). Las acciones de ayuda, más allá de obligaciones especiales en relación con personas con vínculos reconocidos (hijos, amigos, etc.), son loables moralmente pero no obligatorias. El objetivo de GARZÓN VALDÉs al insistir en el carácter trivial del sacrificio es superar la crítica de que si se considera obligatorio ayudar a todos los que necesitan acuciantemente ayuda, por ejemplo a los más de setecientos millones de humanos que viven en la pobreza absoluta, esto conduce irremediablemente a poner las vidas de los más favorecidos al servicio de las de los desfavorecidos, pudiéndose llegar incluso a la pauperización y la destrucción de los propios obligados. Como acabamos de ver esta es una crítica que se puede dirigir contra el estándar exigente de SINGER.

La estrategia argumentativa de GARZÓN VALDÉs es afirmar su tesis, la validez moral de los deberes positivos generales, presentar las objeciones más importantes a dicha tesis, refutar dichas objeciones y, en consecuencia, reafirmar la tesis inicial. El trabajo se divide en tres partes. En la primera se consideran las críticas a los deberes positivos generales basados en su asimetría lógica o conceptual con los deberes negativos generales. Dentro de este grupo, es útil distinguir entre las críticas vinculadas a la distinción clásica entre deberes perfectos e imperfectos y el problema conocido como «dilema de FISHKIN». En la segunda parte, nuestro autor considera los argumentos de ética normativa contra la validez de los deberes positivos generales y, en la tercera, a modo de 
conclusión se apunta a una concepción de la ética basada en la idea de valores, frente a los cuales la imposición de deberes tiene un carácter instrumental.

GARZÓN VALDÉS reconsidera críticamente el alcance de la distinción entre deberes perfectos e imperfectos (defendida por MiLl y re-actualizada por autores liberales como MURPHY, 1979). Los deberes son perfectos cuando $a$ ) su incumplimiento perjudica a los destinatarios de los mismos y $b$ ) estos últimos tienen derecho a exigir su cumplimiento (GARZÓN VALDÉS, 1986: 17). Mientras que no hay ningún problema en entender a los deberes negativos generales como deberes perfectos, sí que se plantean numerosos problemas al considerar perfectos a los deberes positivos generales. $\mathrm{La}$ «imperfección» de los deberes positivos generales se mostraría, según los autores, en diversos «defectos»: que son de imposible cumplimiento (HARDIN, 1976, y FLETCHER, 1976); que el intento de cumplirlos traería peores consecuencias (Wellman, 1982); que, a diferencia de los deberes negativos, el incumplimiento de un deber positivo no implica lógicamente un mal, porque otro tendrá la opción de cumplirlo (TRAMMELL, 1975); que prohíben omisiones en lugar de acciones, de donde se derivan toda una serie de asimetrías: el reproche mayor que se suele atribuir a la acción frente a la omisión, la mayor relevancia causal de la acción frente a la omisión (HONDERICH, 1980), el carácter ilimitado del número de deberes negativos que pueden ser cumplidos frente al necesariamente limitado de los deberes positivos (GLOVER, 1977), los efectos colaterales de la acción moralmente reprochable suelen ser más perniciosos que los de una omisión y, por último, «para que pueda hablarse de una omisión es necesario que existan ciertas expectativas deónticas o empíricas» (GARZÓN VALDÉS, 1986: 20).

Hay que insistir en que GARZÓN VALDÉS introduce en la propia definición de «deberes positivos generales» que su contenido es una «acción de asistencia al prójimo que requiere de un sacrificio trivial». Sobre este presupuesto, argumenta convincentemente que no hay ninguna imposibilidad lógica o conceptual en afirmar, dentro de un sistema moral coherente, la vigencia de deberes positivos generales del mismo modo que se afirma la vigencia de deberes negativos generales.

Con respecto al carácter necesariamente benevolente del cumplimiento de los deberes positivos generales, GARZÓN VALDÉS argumenta que «dañar no significa únicamente empeorar una situación o transformar una situación positiva en una negativa sino también no evitar que un mal se produzca o permitir que continúe, cuando el agente pudo haberlo impedido o superado sin que ello implicara mayor sacrificio de su parte» (ibid.). Con respecto a la duplicación de esfuerzos y las consecuencias negativas del intento de cumplir universalmente con los deberes positivos generales, GARZÓN VALDÉS apela al carácter esencialmente divisible de la obligación de ayuda mutua y a la necesidad de generar instituciones de coordinación. La misma idea de la divisibilidad de la obligación le sirve a nuestro autor para afirmar que la tesis de la opcionalidad no puede establecer una distinción significativa entre deberes negativos y positivos. Cuando no hay tal «divisibilidad», entonces la responsabilidad por no ayudar cae por igual sobre todos los que pueden prestarla. Cuando sí la hay, como es el caso de la obligación de ayudar contra la pobreza y el hambre, entonces no estamos obligados a compensar los incumplimientos de los demás obligados. Finalmente, si la «opcionalidad» se refiere al hecho de que no podemos estar seguros de si nuestra omisión dañará a alguien, puesto que otro puede hacer aquello que nosotros no hemos hecho, 
de acuerdo con GARZÓN VALDÉS, dependiendo de las circunstancias, lo mismo puede ocurrir con los «deberes negativos» (GARZÓN VALDÉs, 1986: 23). En relación con los argumentos vinculados a la distinción entre acciones y omisiones, GARZÓN VALDÉS es muy claro al afirmar la prioridad de las cuestiones normativas sobre las conceptuales. Al tiempo que afirma «que para que pueda hablarse de omisión es necesario haber aceptado antes la existencia de la obligación» (GARZÓN VALDÉs, 1986: 27), señala que «esto es precisamente lo que niegan quienes recurren al argumento de la diferencia entre acción y la omisión» (ibid.). Para GARZÓN VALDÉS, se trata de proteger un valor, por ejemplo la vida, por medio del cumplimiento de deberes negativos y positivos, y la relevancia de la diferencia entre unos y otros sólo se puede establecer en tanto que instrumentos en defensa de ese valor.

James S. FISHKIN ha sostenido que la cuestión de la validez de los deberes positivos generales nos enfrenta al siguiente dilema: o bien afirmamos la validez de los deberes positivos generales y debemos abandonar nuestra comprensión de la moralidad con una estructura básica que distingue entre actos moralmente indiferentes, supererogatorios y obligatorios, o bien debemos negar la validez de los deberes positivos generales y, entonces, renunciar a principios básicos de la moral como la imparcialidad y, en última instancia, al propio «punto de vista moral» (FISHKIN, 1982). A juicio de GARZÓN VALDÉS, por el contrario, el dilema se puede evitar condicionando la existencia de deberes positivos generales al cumplimiento de las siguientes reglas: 1) el sacrificio trivial está temporalmente delimitado, es decir, su reiteración es exigible después de haber pasado un cierto tiempo de recuperación que restituya al obligado a la situación en que se encontraba antes de realizar el sacrificio trivial; 2) nadie está moralmente obligado a compensar la no realización de sacrificios triviales por parte de los miembros de su clase o comunidad cuando se trata de deberes positivos divisibles; 3 ) nadie está moralmente obligado a realizar un sacrificio trivial cuando quien lo solicita está en condiciones de superar por sí mismo su situación de penuria, y 4) los sacrificios triviales deberán ser coordinados sobre la base de la división del trabajo y su especialización» (GARZÓN VALDÉS, 1986: 24).

En la segunda parte de su trabajo, GARZÓN VALDÉs defiende su posición de ética normativa a partir de refutar los argumentos contrarios de la tradición liberal (o libertaria) norteamericana, la cual ha criticado los deberes positivos generales por ser contrarios al principio de libertad y/o igualdad y que sostiene que no son deberes indispensables para la convivencia humana. Para GARZÓN VALDÉS, quienes argumentan en favor de una esfera máxima de no interferencia apelando a la libertad, al «derecho de toda persona a que la dejen tranquila» (BRANDEIS), consideran que dentro de esa esfera de libertad las personas deben recoger los frutos de su éxito pero también asumir las consecuencias de sus fracasos, sin que la intervención correctora del Estado busque una injustificable «igualdad en el resultado». A juicio de nuestro autor, esta postura es sencillamente incongruente con la propia justificación de los deberes negativos, que también producen una igualación en el resultado, «haciendo que el débil sea igual que el fuerte» (GARZÓN VALDÉs, 1986: 29). Frente al argumento de la igualdad que sostiene que los deberes positivos no se pueden universalizar en cuanto a los beneficiarios, replica GARZÓN VALDÉS que «creer que universalización significa la eliminación de toda distinción entre los agentes morales es confundir universalización 
con incondicionalidad y establecer un igualitarismo que sí destruye la posibilidad de vigencia de preceptos generales» (GARZÓN VALDÉs, 1986, 30). Finalmente, GARZÓN VALDÉS afirma que la vigencia de los deberes negativos generales no es suficiente para garantizar la vida en sociedad.

Ya en la tercera parte, como conclusión, se ahonda en esta idea de la simetría entre los deberes afirmando que los mismos, positivos o negativos, «no constituyen un fin en sí mismos sino que tienen un carácter eminentemente instrumental, es decir, asegurar la protección de bienes que se consideran valiosos», de donde resulta una concepción de la ética como un conjunto de reglas «con fines pragmáticos». La evolución del Estado liberal abstencionista a un Estado social pone de manifiesto la insuficiencia del modelo lockeano para garantizar bienes que son primarios. Sin embargo, en el plano de la moral individual, «tampoco el Estado social exime de la obligación de cumplir con los deberes positivos generales, cuya justificación es la misma que la de los deberes negativos generales: la protección de bienes que se consideran valiosos» (GARZÓN VALDÉS, 1986: 32).

\subsection{Observaciones críticas al planteamiento de GARZÓN VALDÉS}

En el mismo número de la revista Doxa donde se publica el artículo de GARZÓN VALDÉS, Juan Carlos BAYÓN y Francisco LAPORTA hicieron una revisión crítica del mismo. Creo que merece la pena exponer sus lineamientos principales, no sólo por lo que aportan a la valoración de las tesis de GARZÓN VALDÉS, sino también porque sus puntos de vista alternativos pueden servir para alcanzar algunas conclusiones sobre el tema que nos ocupa.

Juan Carlos BAYÓN, en primer lugar, señala que al tratar la cuestión del análisis del par conceptual daño y beneficio, GARZÓN VALDÉS no siempre ha mantenido separados el plano conceptual y el sustantivo (BAYÓN, 1986: 40), de modo que no habría advertido que para saber si una concreta acción es el cumplimiento de un deber positivo de ayuda mutua o un acto supererogatorio de beneficencia es necesaria una toma de posición previa sobre qué es lo debido en una situación determinada.

En segundo lugar, BAYÓN aborda la que considera la cuestión más espinosa: «Poner límites a nuestros deberes positivos, de modo que no nos veamos abocados a la extraordinariamente exigente posición de Singer» (BAYÓN, 1986: 35). A su juicio, la propuesta de GARZÓN VALDÉS no es convincente en este punto, porque no se justifica, desde el punto de vista de una moral crítica, por qué el sacrificio que conlleva el cumplimiento de los deberes positivos generales no ha de superar lo «trivial» (BAYÓN, 1986: 44). Es cierto que, como sostiene Garzón VALDÉs, el dilema de FishKIN es superable, pero se da por supuesto que la exigencia de partida debe ser siempre la de un altruismo mínimo. Adicionalmente, BAYÓN señala que la idea de «sacrificio trivial» es oscura por dos razones: primera, porque el principio sólo puede tener sentido si exige la paradójica idea de un «máximo sacrificio trivial posible» (lo cual, en su opinión, es tan difícil como determinar cuál es el hombre más alto de los hombres bajos del mundo) y, segunda, porque la noción de «sacrificio» presupone el derecho moral a aquello de lo que prescindimos para ayudar a los necesitados, lo cual nos conduce a 
asumir la justicia del actual esquema de reparto (BAYÓN, 1986: 46 y 47). Por último, sostiene BAYÓN que hay una incoherencia entre la tesis de la simetría entre deberes negativos y positivos, defendida por GARZÓN VALDÉs, y el hecho de que se nos exija en cumplimiento de nuestros deberes negativos un sacrificio mucho mayor que en los positivos: por mucho interés que tenga en matar a otro, mi obligación es abstenerme de hacerlo.

Para BAYÓN, la noción clave en la determinación de los límites de los deberes positivos generales es la de autonomía, el valor de elegir nuestro propio plan de vida, ya que, como advierte NiNO, «la concepción que estipula el deber moral de evitar cualquier mal que podamos evitar compele a adoptar como único plan de vida el del buen samaritano» (NINO, 1984: 208). La protección de la autonomía individual establece un límite a las razones basadas en el bienestar general y permiten construir la distinción entre los actos moralmente obligatorios y los supererogatorios (aquellos que sería mejor hacer pero que por «razones de autonomía» no son exigibles). Partiendo de una concepción de la autonomía como «capacidad de optar entre diferentes planes de vida», BAYÓN concluye defendiendo que para que haya un reparto digno de la autonomía, habría que aplicar el principio de diferencia rawlsiano y que dado que la autonomía exige, además de libertad e información, de recursos mínimos, nadie podría negarse justificadamente a prestar ayuda hasta que se alcanzara el esquema de distribución justo, aunque ello implique un sacrificio algo más que trivial. En conclusión, BAYÓN reconoce que su posición es bastante próxima a la de SINGER: «Nuestras convicciones morales comunes la juzgan excesiva, pero no acierto a ver el tipo de argumento que nos permitiría llegar a una conclusión distinta» (BAYÓN, 1986: 52).

Francisco LAPORTA por su parte afirma que la posición de GARZÓN VALDÉS, como la de SINGER, asume «que la producción por omisión de ciertos efectos (p. ej. el hambre en zonas del tercer mundo) es el fundamento o razón que ha de utilizarse para adscribir responsabilidad moral (y no sólo causal) a aquellos individuos que omiten la realización de ciertas acciones (p. ej., ciertos sacrificios triviales)» (LAPORTA, 1986: 56). Para que podamos afirmar que una omisión es causa, precisa LAPORTA, es necesario que se constaten los siguientes elementos: «a) Un conjunto de condiciones relevantes coherentes con y simultáneas a $[\ldots]$; b) $[\ldots]$ una acción a realizar que, en virtud de $[\ldots]$; c) $[\ldots]$ una conexión nómica produce $[. .$.$] ; d) [...] la evitación de cierto estado de cosas» (LAPOR-$ TA, 1986: 57). En los denominados casos de moralidad «face to face», cabe delimitar con precisión estos elementos, de modo que cabe igualmente señalar que un agente es responsable moralmente del daño que causó con su omisión; la responsabilidad moral se fundamenta en la responsabilidad causal de manera directa. Ahora bien, advierte LAPORTA, fuera de estos casos y, en concreto, en lo referido al problema del hambre en el tercer mundo, el esquema propuesto para verificar la causación por omisión se complica de tal manera que «no resulta extraño que, para esos supuestos, el "sentido común" dictamine que las acciones son más culpables que las omisiones» (LAPORTA, 1986: 58). Esto no se resuelve sino que se complica introduciendo en la noción de omisión, tal y como hace GARZÓN VALDÉS, un componente deóntico. Se complica, sostiene LAPORTA, si ante las dificultades para adscribir responsabilidad causal por una omisión a un individuo, se le atribuye igualmente responsabilidad moral por omitir porque se entiende por «omisión» no hacer lo que se debe hacer. 
A juicio de LAPORTA, la salida a este enredo se encuentra en la teoría de la causación colectiva y de la responsabilidad colectiva, «para derivar a partir de ellas los supuestos de responsabilidad individual consiguientes» (LAPORTA, 1986: 81). En los supuestos de causación por omisión colectiva, el resultado de la omisión colectiva es diferente del que produce cada una de las omisiones individuales. LAPORTA sugiere que «puede distinguirse entre la responsabilidad colectiva por la omisión colectiva y las responsabilidades individuales por las omisiones de los integrantes del colectivo» (LAPORTA, 1986: 61) De esta manera concluye que «para estos supuestos de gran complejidad, el único significado analítico que podemos atribuir a la existencia de un deber positivo general, por ejemplo de ayuda mutua, que gravite sobre un colectivo, consiste en articular un conjunto de deberes positivos especiales que graviten sobre los miembros de ese colectivo» (LAPORTA, 1986: 62). En última instancia, LAPORTA muestra sus dudas sobre que este problema sea enfrentado en el contexto de la moralidad interindividual y no «a partir de una moralidad pensada para las instituciones», lo cual es reflejo de la «reprivatización» de demanda básicas de moralidad «que parece tener como objetivo desplazar las responsabilidades de la estructura institucional de los gobiernos y de las políticas internacionales para reubicarlas en la esfera de las actitudes individuales» (LAPORTA, 1986: 63).

Teniendo en mente las observaciones de BAYÓN y LAPORTA, trataré de exponer a continuación mi propia valoración de las tesis de GARZÓN VALDÉS y su comparación con las de DwORKIN. En primer lugar, hay que insistir en que cuando GARZÓN VALDÉS introduce en la definición de «deberes positivos generales» la noción de «sacrificio trivial» señala implícitamente uno de los objetivos de su artículo: refutar a quienes sostienen que, por razones conceptuales, normativas o prácticas, ni siquiera sería exigible un sacrificio trivial como contenido de un deber positivo general. A mi juicio, nuestro autor tiene éxito al mostrar las debilidades de esas posiciones que podríamos calificar de «liberales extremas» y, dado que desde la fecha de publicación del artículo hasta la actualidad dicho extremismo no ha parado de crecer y extenderse (de globalizarse), el catálogo de contra-argumentos que nos ofrece GARZÓN VALDÉs no es nada desdeñable. Por otro lado, se apunta una crítica de mucho alcance sobre la prioridad del análisis conceptual para determinar la validez de tesis normativas. Hemos visto que BAYÓN le reprocha no haber mantenido convenientemente separados los sentidos descriptivos y normativos en relación con los conceptos de daño y beneficio. En una breve contra-réplica, GARZÓN VALDÉS sostiene que «las lesiones de la autonomía (sea por acción o por omisión) "dañan" no porque estén prohibidas sino que justamente se las prohíbe por que se considera que la autonomía de la persona es un bien valioso» (GARZÓN VALDÉS, 1986b: 66). En el mismo sentido, al tratar de la expectativa deóntica implícita en la omisión de ayudar, señala que si los argumentos en favor de los deberes positivos generales son convincentes «la distinción entre acción y omisión pierde su relevancia» (GARZÓN VALDÉS, 1986: 28). Finalmente, en esta línea, conviene recordar la advertencia de nuestro autor: «la ética no es un lujo o un ejercicio más o menos ingenioso de los filósofos sino un conjunto de reglas con fines pragmáticos» (GARZÓN VALDÉs, 1986: 32). Aquí podemos encontrar, creo que sin forzar la interpretación, una similitud con la tesis sistemáticamente desarrollada por DwORKIN en la primera parte de Justicia para erizos de que no hay metaética en el significado ordinario del término, puesto que toda cuestión metaética es ya una 
cuestión moral ${ }^{16}$. En este mismo sentido creo que puede interpretarse el estudio de Manuel ATIENZA de la parte de la obra de GARZÓn VALDÉs dedicada a los temas de ética normativa, en la cual, señala ATIENZA, «el análisis ha pasado a ser, en general, un método» (ATIENZA, 1993: 22). ATIENZA propone entender la concepción de la filosofía moral de GARZÓN VALDÉS como un sistema de principios, reglas y tesis, y sugiere que «si se quiere» esta división puede entenderse como elementos de ética normativa (principios y reglas) y de metaética (tesis). Sin embargo, en cuanto a las tesis que servirían de sustento al principio que afirma la existencia de deberes positivos generales, ATIENZA señala las siguientes: «(T1) los deberes éticos son instrumentos para la protección de bienes que se consideran valiosos; (T2) la justificación de los deberes generales positivos es la misma que la de los negativos: la protección de los bienes primarios, o de las necesidades básicas, de los seres humanos; (T3) la justificación moral de los deberes positivos generales en las relaciones interpersonales implica, en el plano de las instituciones, que el único Estado que puede aspirar a ser legítimo es el Estado social de Derecho» (ATIENZA, 1993: 23 y 24). Si no me equivoco, estas «tesis» son metaéticas tan sólo en el sentido de que no son directivas, ni principios ni reglas, pero no lo son en el sentido de externas al discurso de la ética normativa.

En segundo lugar, aunque la prioridad de GARZÓN VALDÉS sea refutar a quienes niegan que sea exigible ni siquiera un «sacrificio trivial» para ayudar a remediar la pobreza absoluta, lo cierto es que su pretensión parece ser también la de que este «sacrificio trivial» es todo lo exigible desde el punto de vista ético. Creo que tiene razón BAYÓN cuando critica que se trata de una tesis que requeriría de mayores aclaraciones y con un déficit de argumentación. La insistencia de GARZÓN VALDÉs en el carácter divisible de las obligaciones de ayuda y su inserción en un esquema de coordinación de esfuerzos sugiere, en la línea de las preferencias de LAPORTA, que la cuestión de ética individual sobre el alcance de la responsabilidad personal ante la pobreza absoluta debe transformarse en una cuestión diferente de «moralidad política»: por ejemplo, los intentos de globalizar la teoría de la justicia al objeto de producir diseños institucionales globales que remedien la pobreza (TuRÉGANO, 2010). GARZÓN VALDÉs parece abogar por una profundización del Estado social también hacia fuera. Pero lo cierto es que, como el mismo GARZÓN VALDÉS señala en contestación a LAPORTA, su tema es la responsabilidad moral individual, que es una cuestión previa a si el Estado o las instituciones deben asegurar el cumplimiento de tales deberes (GARZÓN VALDÉS, 1986: 68).

A mi juicio, la propuesta de exigir una contribución a cualquiera que esté en condiciones de ayudar hasta el límite de un sacrificio trivial resulta similar al estándar

16 Para apoyar este punto, DwORKIN recurre a una ilustración directamente relacionada con el problema que nos ocupa: «Jack está sufriendo mucho y para ti sería fácil ayudarlo. En consecuencia, por esa sola razón, tienes el deber moral de prestarle ayuda». Si este, tal y como se presenta — continúa DwORKIN—, es un buen argumento, debe intervenir entonces algún principio acerca de qué hace bueno a un argumento. ¿Cuál es ese principio? No puede ser ninguna forma de inducción o generalización, porque estas supondrían que uno ha tenido un deber moral en el pasado, y eso es un supuesto moral. No puede ser un principio de deducción o vinculación semántica. Hace falta otra cosa, y esa otra cosa debe ser algo — una premisa oculta o un supuesto sobre la naturaleza del buen razonamiento moral— que esté imbuido de fuerza moral. Sí, el hecho de que alguien frente a nosotros muestre a las claras que está sufriendo mucho parece ser por sí solo una razón por la cual, de poder, deberíamos ayudarlo. No hace falta decir nada más. Pero supongo que pensamos eso porque aceptamos naturalmente, como algo que huelga decir, una responsabilidad general de ayudar a las personas en grave necesidad cuando nos resulta fácil hacerlo» (DWORKIN, 2014: 65 y 66). 
público o sensato de SINGER; se trata de un principio organizativo que quizás merece la pena defender públicamente como fundamento de una norma jurídica. Sin embargo, como principio moral asumido en primera persona, en el balance de razones sobre cómo debo vivir para asumir mi responsabilidad moral, resulta opaco. ¿Por qué no debo hacer algo más que un sacrificio trivial para ayudar a los que lo necesitan? En mi opinión, DwORKIN aborda mejor el problema al situarlo en primer lugar en el ámbito de lo que él denomina ética. La pregunta por mis responsabilidades con los otros no se debe separar de la pregunta sobre la responsabilidad hacia uno mismo, sobre qué es necesario para vivir bien, cuál es la concepción de la dignidad humana que vamos a asumir autónomamente y que servirá para determinar nuestros propios parámetros de una vida bien vivida.

Por último, quisiera destacar que cuando GARZÓN VALDÉs reconsidera, al hilo de los comentarios críticos de LAPORTA, la vinculación entre responsabilidad causal y responsabilidad moral, dice lo siguiente: «quien participa en una elección o no arroja basura al río lo hace distanciándose de sus propios intereses y siguiendo su propia convicción moral de lo que es correcto. Asume en este sentido su "responsabilidad moral" y por ello es posible formular un reproche moral a quien no actúa de esta forma, sin que importe la relevancia fáctica de su acto» ${ }^{17}$ (GARZÓN VALDÉS, 1986b: 68). Si interpreto correctamente este último inciso, GARZÓN VALDÉS apela al carácter prioritario de la buena voluntad, en sentido kantiano, sobre las consecuencias, pero igualmente apela en otro momento, como hemos visto, a una concepción pragmatista de la ética en la que los deberes son instrumentos al servicio de los valores, algo que se aleja del rigorismo y absolutismo kantiano. A mi juicio, la tensión que se aprecia aquí tiene que ver con que el principio moral de los deberes positivos generales parece ser derivación de un principio más básico que le sirve de fundamento. Siendo el primero un principio en cierta medida condicionado y el segundo un principio en sentido kantiano incondicionado o absoluto. Vistas así las cosas, el que el sacrificio exigido sea trivial (dejando a un lado el problema de indeterminación de «trivial») es ya una concreción o especificación de ese principio más profundo a la luz de ciertas circunstancias: en particular, el que la obligación sea divisible y exista la suficiente coordinación de esfuerzos al respecto. El problema está en que tal principio condicionado no puede aplicarse si no se dan las condiciones de aplicación: si no hay una estructura organizativa que coordine el cumplimiento de las obligaciones (divisibles), entonces deberíamos acudir a otro principio para determinar nuestras obligaciones.

\section{CONCLUSIONES}

Tratando de integrar la noción de «mala suerte moral» en su concepción de los dos ideales de vida: vivir bien y tener una buena vida, DwORKIN sostiene que podemos sentir remordimientos que no siguen a la culpa, que no se originan en un defecto del ideal de vivir bien, sino que tienen su origen en injusticias de las que no somos responsables pero que limitan o arruinan el disfrute de una buena vida (DWORKIN, 2011: 201 y 202). Creo que la situación de injusticia global en la que vivimos, de la cual el hambre y la

\footnotetext{
17 La cursiva es mía.
} 
pobreza absoluta son la manifestación más cruda, constituye para todos, no sólo para los desfavorecidos, una «mala suerte moral» que deja fuera de nuestro alcance el poder disfrutar plenamente de una «buena vida» en armonía con un ideal de «vivir bien». En otro lugar he defendido el derecho a un mundo justo, un derecho frente al Estado a que se promuevan las condiciones en las que sea posible cumplir con nuestros deberes positivos generales con eficacia, un derecho en última instancia a vivir en un mundo sin pobreza (Alemany, 2012: 71). Pero la realidad es que estamos muy lejos, y es dudoso siquiera si andamos en la dirección correcta, de que se generen las condiciones para un mundo justo. En conclusión, la mala conciencia de los que Peter SINGER llama «ricos absolutos» y que nos empuja, con buena voluntad, a tratar de buscar una respuesta en la filosofía moral sobre nuestra responsabilidad moral frente a la pobreza, no puede (no debe) desaparecer del todo, por más que tratemos de ser íntegros y cumplir con las obligaciones que nos parezcan justificadas.

La distinción entre actos obligatorios y actos supererogatorios es más clara cuando se refiere a las relaciones interpersonales, como fundamento de una distinción entre moral pública y privada, que cuando juega en una deliberación en primera persona sobre cómo debemos comportarnos. La mayoría de las personas que se comprometen radicalmente en la ayuda a los necesitados suelen afirmar que hacen lo que creen que es su deber, igualmente quienes arriesgan su vida valientemente para salvar la de un desconocido. Habrá quien piense que se trata sólo de una forma de hablar modesta, o de falsa modestia, pero, en mi opinión, se pone de manifiesto esa integración recíproca entre la ética y la moral que defiende DwORKIN. Si soy el tipo de persona que no se arredra ante un desafío o que no permite una injusticia, asumo una obligación ética, frente a mi mismo, que genera una obligación moral frente a los otros. En el trasfondo de todo hay un objetivismo de los valores porque no valoro tal forma de ser porque la quiero, sino que la quiero porque la valoro.

DWORKIN señala que tenemos derecho a luchar por obtener una buena vida, pero respetando ciertos límites esenciales para la dignidad humana, la prioridad que se nos concede para determinar qué tipo de persona queremos ser y comprometernos con un plan de vida y un estilo o un carácter determinados no puede implicar una actitud de falta de respeto, un insulto, a la dignidad de los otros. Este principio me parece compatible con los de SINGER, tanto en su versión estricta como en la pública, y el de GARZÓN VALDÉs. Es compatible con el de SINGER en su versión más estricta porque podemos pensar que los principios éticos de auto-respeto y autenticidad son de una importancia moral comparable al daño que no evitamos por ser fieles al proyecto de vida que hemos escogido. Es compatible con la versión pública de SINGER o el principio del sacrificio trivial de GARZÓN VALDÉS porque es casi seguro que compartir una pequeña parte de nuestra riqueza (irrelevante, en definitiva, para el bienestar) no compromete el debido auto-respeto, a salvo que nuestro plan de vida sea en sí mismo un insulto a la dignidad de los otros. Pero el planteamiento de DWORKIN me parece más profundo y fecundo: utilizando una expresión de SINGER, tiene capacidad de operar como un círculo en expansión.

En primer lugar, DwORKIN nos aporta una interpretación moral del problema de la particularización y de la proximidad (aplicando su «principio de HuME» al discurso moral), que permite integrar algunas intuiciones muy fuertes sin recaer en una confu- 
sión entre moral crítica y moral social. Cuanto más particularizada y próxima está la víctima, nuestra negativa a ayudar es más expresiva del desprecio por la vida de los otros. Del mismo modo ocurre cuando el contraste entre el costo de ayudar y el beneficio de la ayuda es muy grande.

En segundo lugar, el principio de DWORKIN es holístico, no se trata sólo de cumplir una determinada prestación, sino también de definir cierto estilo de vida o carácter. Tanto en la propuesta «sensata» de SINGER como en el sacrificio trivial de GARZÓN VALDÉS se toma la contribución económica como modelo del tipo de obligación que hay que satisfacer. No cabe duda de que es importante. Sin embargo, no creo que sea el modelo. De un lado, en las últimas décadas se ha desarrollado un ingente cuerpo de conocimiento sobre las causas de la pobreza y las vías para remediarla. Como ha puesto de manifiesto Amartya SEN entre otros muchos, la libertad de prensa o la democracia son igualmente salvaguardas contra la pobreza (2000). En el mundo contemporáneo, es una ingenuidad contribuir con dinero a una organización de ayuda y al tiempo desentenderse del modo en que se hacen rentables los ahorros; o prestar ayuda a una organización que protege a la infancia al tiempo que se consumen los productos de una empresa que explota a los niños.

En general, el excesivo énfasis en la cuestión de los deberes u obligaciones concretas oscurece otros aspectos importantes de la cuestión, en particular, lo referido a la noción de virtud y su vinculación con los valores morales. La ética de la virtud no se opone a la ética de las normas o de las consecuencias. En realidad, importan las normas, las consecuencias y también el carácter moral de los individuos. Desde el punto de vista dworkiniano, hay acciones cuyo valor no está ni en las consecuencias previsibles de la misma para otros, ni en que constituyan el cumplimiento de una obligación, sino en cómo contribuyen a conformar un carácter moralmente valioso para la persona que las realiza. Por ejemplo, la vieja costumbre doméstica, quizás en desuso, de comer todo lo que se sirve en la mesa por no tirar la comida, puede que no resista el escrutinio de una ética deontológica o utilitarista, pero es perfectamente comprensible en términos de una ética de la virtud: no se trata tanto de hacer algo determinado como de ser de cierta manera.

Pensemos en la virtud de la austeridad. Desde luego, dado que los recursos son limitados, es necesario señalar un conjunto de obligaciones sobre el uso correcto de dichos recursos, ya sea a partir de consideraciones basadas en el derecho de los otros, asumiendo un punto de vista imparcial, o desde consideraciones basadas en las mejores consecuencias para todos. Pero el asunto de ser austero no se reduce a cumplir con esas obligaciones, porque se orienta a conformar nuestro carácter y nuestros deseos a lo correcto, de manera que dichas obligaciones pasen a formar parte de lo que verdaderamente queremos hacer. No creo que el problema de la pobreza absoluta tenga una solución permanente mientras exista lo que me atrevo a llamar el problema de la «riqueza obscena», la cual constituye un claro insulto a la dignidad de los otros. Me parece que mientras los ciudadanos de los países desarrollados vivamos como derrochadores, tomemos como modelos de éxito social a los ricos, nos reconozcamos fundamentalmente como consumidores, etc., será muy difícil un cambio significativo. En este sentido, más allá de si nuestras acciones particulares tienen o no un efecto relevante en el mundo, de si las mismas son suficientes o deben compensar las faltas de los 
otros, hacemos lo correcto toda vez que tratamos de contaminar menos, de no hacer gastos superfluos, de no acumular riquezas innecesarias, etcétera.

Igualmente, tenemos la virtud de la integridad. De acuerdo con la misma, debemos tener la disposición a hacer lo que creemos correcto a pesar de que ello suponga algún sacrificio. Desde luego, la integridad es mucho más fácil si nos conformamos con menos, si somos austeros. Las virtudes se refuerzan unas a otras. Sabemos mucho sobre cómo prevenir el hambre. Sabemos, por ejemplo, que la emancipación de la mujer juega un papel decisivo. Por ello, no podemos prestar apoyo a organizaciones, ideologías o prácticas machistas. Sabemos que el que haya medios de planificación familiar al alcance de las mujeres es igualmente decisivo para prevenir la pobreza. De nuevo, debemos defender públicamente los derechos a la libertad reproductiva y mostrar nuestro rechazo a quienes quieren limitar dicha libertad, poniendo a las mujeres entre la espada y la pared de la abstención sexual o la reproducción. Igualmente, los compromisos con la democracia, la libertad de prensa, la independencia judicial, etc., son fundamentales si es que queremos ser íntegros con respecto a la convicción de que la pobreza absoluta es un mal y ello con relativa independencia de si nuestro compromiso particular hace la diferencia. Por último, si queremos ser justos, tal y como sostienen los defensores del cosmopolitismo, deberíamos estar dispuestos a renunciar como sociedad a nuestro poder para imponer en los organismos internacionales los arreglos que más nos interesan, en detrimento de arreglos equitativos aunque no sean los mejores para nosotros. No debemos pensar que el mejor gobierno es el que saca lo máximo para nosotros, sino el que saca lo máximo siendo justos. La virtud de la integridad impone, en ocasiones, límites a la realización de nuestros deseos, pero, como ya se ha dicho, esos límites pueden resultar menos gravosos si somos austeros.

Para ARISTÓTEles la ética es fundamentalmente una ética de las virtudes. Desde su punto de vista, la virtud es una disposición del carácter a actuar de cierta manera, que se sitúa entre dos extremos inadecuados: por ejemplo, el valiente es quien tiene la disposición de actuar con valentía, la cual es un término medio entre la cobardía y la temeridad. Ser valiente es compatible con no serlo en alguna concreta y excepcional circunstancia y no hay un límite preciso entre serlo y no serlo, ya sea por cobarde o ya sea por temerario. Podemos señalar modelos de personas valientes más que un código de obligaciones de arrojo. Por eso en el mundo clásico los modelos eran tan importantes y la emulación era el método principal de perfeccionamiento moral. En la sociedad contemporánea, el mercado no va a dejar que nadie se convierta en un modelo universal ejemplificando la austeridad. Los modelos globales venden algo, en general formas de vida opulentas. Pero la realidad es muy compleja y hay muchos ejemplos a seguir, aunque haya que tener cierta disposición de ánimo para encontrarlos. La vida de quienes se comprometen totalmente con los más necesitados no tiene que ser necesariamente una «acusación», sino que puede constituir un modelo para el arduo trabajo de la construcción de una ética personal, de un modo de vivir bien.

En tercer lugar, al integrar las nociones éticas y morales en la idea de «vivir bien», podemos ver con más claridad que, en muchas ocasiones, el incumplimiento de nuestros compromisos con los demás tiene las mismas fuentes que el incumplimiento de los compromisos con nosotros mismos. La debilidad de la voluntad opera en ambas direcciones. Pues bien, las mismas herramientas que utilizamos para superar nuestra 
debilidad de voluntad en relación con nosotros mismos pueden ser utilizadas en relación con nuestras obligaciones de ayuda. Por ejemplo, del mismo modo que suscribo un plan de pensiones que me obliga a ahorrar para mi vejez, es más seguro que cumpliré mejor mis obligaciones con los otros si, en lugar de hacer donaciones de dinero puntuales, comprometo una cantidad fija mensual con una organización de cooperación. Sabemos, además, que una vez tomada la decisión de contribuir con una cuota periódica raramente se modifica.

En último lugar, quisiera referirme a la cuestión de la felicidad personal frente a la calamidad de la pobreza. DwORKIN no sostiene algo tan poco plausible como que hacer lo correcto contribuya siempre a tener una vida mejor (como valor producto) $\mathrm{y}$, a la inversa, tampoco sostiene el ingenuo punto de vista de que hacer lo incorrecto vaya a empeorar necesariamente la vida que disfrutamos. Sin embargo, creo que tiene razón cuando sostiene que es un error concebir la moral como un obstáculo para lograr una buena vida. Por ello creo que es muy importante reivindicar el viejo derecho a buscar la propia felicidad y esa integración coherente entre la ética y la moral. Una vez que tomamos conciencia de que la responsabilidad hacia nuestra propia vida implica integrar los dos ideales, el ético y el moral, ello no nos pone necesariamente en una situación de desventaja frente a los que viven ignorando el sufrimiento ajeno: en la medida en que consigamos una mayor coherencia entre nuestra concepción de lo que es vivir bien y nuestra concepción de una buena vida, tendremos más posibilidades de alcanzar una felicidad profunda y estable. Paradójicamente ha sido Peter SINGER quien más ha insistido en los últimos tiempos en este punto: el altruismo no se opone a la felicidad individual. A su juicio, es necesario desarrollar una «cultura de la donación» que contrarreste la dominante cultura del consumo. De nuevo conforme a la tradición clásica, dicha cultura de la donación sólo puede extenderse a partir de la emulación, por lo cual su proyecto «The live you can save» se basa en compartir las experiencias de ayuda. Lamentablemente, los modelos que genera la sociedad de consumo son casi exclusivamente modelos de «buena vida». La denominada cultura del éxito no es más que la cultura de la vida como valor producto en detrimento de la cultura de la vida como valor actuación.

\section{BIBLIOGRAFÍA}

Alemany, M., 2012a: «Una nota sobre la responsabilidad moral individual frente a la calamidad del hambre», Obets. Revista de Ciencias Sociales, vol. 7, núm. 1, 15-29.

- 2012b: «El derecho a un mundo justo. Hambre, responsabilidad de los Estados y globalización», en M. Alemany (ed.), La calamidad del hambre, Lima: Palestra.

Atienza, M., 1993: «La filosofía moral de Ernesto Garzón Valdés», en Derecho, ética y política, Madrid: Centro de Estudios Constitucionales, 21-32.

- 2013: Curso de argumentación jurídica, Madrid: Trotta.

BAYÓN, J. C., 1986: «Los deberes positivos generales y la determinación de sus límites. Observaciones al artículo de Ernesto Garzón Valdés», Doxa. Cuadernos de Filosofía del Derecho, vol. 3, 35-54.

Dworkin, R., 2011: Justice for Hedgehogs, Cambridge: Harvard University Press.

FishKIn, J., 1982: The Limits of Obligation, New Haven: Yale University Press. 
FletCHeR, J., 1976: «Feeding the Hungry: An Ethical Appraisal», en G. LuCAS (ed.), Lifeboat Ethicsm New York.

GARZÓN VALDÉS, E., 1986: «Los deberes positivos generales y su fundamentación», Doxa. Cuadernos de Filosofía del Derecho, vol. 3, 17-34.

GARZÓN VALDÉs, E., 1986b: «Algunos comentarios críticos a las críticas de Juan Carlos Bayón y Francisco Laporta», Doxa. Cuadernos de Filosofía del Derecho, vol. 3, 65-68.

- 1993: «No pongas tus sucias manos sobre Mozart. Algunas consideraciones sobre el concepto de tolerancia», en Derecho, ética y politica, Madrid: Centro de Estudios Constitucionales, 401-415.

- 2012: «Algunas reflexiones sobre el problema de la desnutrición desde el punto de vista de la bioética», en M. Alemany (ed.), La calamidad del hambre, Lima: Palestra.

GLOver, J., 1977: Causing Death and Saving Lives, London.

Hardin, G., 1976: «Carrying Capacity as an Ethical Concept», en G. LuCAS (ed.), Lifeboat Ethics, New York.

HONDERICH, T., 1980: Violence for Equality, Suffolk.

LAPORTA, F., 1986: «Algunos problemas de los deberes positivos generales. Observaciones a un artículo de Ernesto Garzón Valdés», Doxa. Cuadernos de Filosofía del Derecho, vol. 3, 55-63.

MuRPHY, J., 1979: Retribution, Justice and Therapy, London.

NAGEL, Th., 2006: Igualdad y parcialidad. Bases éticas de la teoría política, Barcelona: Paidós.

RAZ, J., 1991: Razón práctica y normas, Madrid: Centro de Estudios Constitucionales.

Singer, P., 1972: «Famine, Affluence and Morality», Philosophy and Public Affairs, vol. 1, 3, 229-243.

- 1981: The Expanding Circle, New Jersey: Princeton University Press.

- 1995: Ética práctica, Cambridge: Cambridge University Press.

- 2012: Salvar una vida. Cómo terminar con la pobreza, Madrid: Clave Intelectual.

SLOVIC, P., 2007: «If I look at the mass I will never act: Psychic numbing and genocide», Judgement and Decision Making, 2:2, 79-95.

ThaleR, R., y Sunstein, C., 2009: Un pequeño empujón (Nudge), Taurus: Madrid.

Trammell, R., 1975: «Saving Life and taking life», Journal of philosophy, 22.

TurÉGAnO, I., 2010: Justicia global: los límites del constitucionalismo, Lima: Palestra.

Wellman, C., 1982: Welfare Rights, Totowa: New Jersey. 